\title{
Can You Traverse It?
}

\section{On Using Immersion as a Validation Tool When Learning to Produce Three Dimensional Inhabitable Figures}

\author{
Iván Pajares Sánchez ${ }^{(\bowtie)}$ and Mara Sánchez Llorens \\ Polytechnic University of Madrid, Madrid, Spain \\ ivan.pajares@upm.es
}

\begin{abstract}
If we consider that "creating architecture, as viewed from our area of interest, consists in the production of three-dimensional inhabitable figures" (Burgaleta 2019) and we center our teaching around that fact, we will eventually be in need of some sort of procedure to provide our apprentices with the tools to verify that the spaces they produce - said three dimensional figures - are inhabitable.

In this paper we relate a sequence of classes we setup as an extended assignment. Apprentices are initiated in (1) the production of three-dimensional spaces using cheap, open and conventional graphical techniques - which have low complexity and favor imaginary exploration of space - and (2) the actual validation of the produced space habitability through interactive immersion.

We favor a working scheme based on the intersection of traditional and digital graphical techniques to facilitate the creative process.

The outlined validation procedure is accessible, easy and does not get in the way, that is: it has a small learning curve that enables its use by apprentices with very little previous knowledge of $3 \mathrm{D}$ applications. In this way, they can concentrate on the production of three-dimensional spaces without the associated complexity of realistic rendering and set up of interactive 3D simulations.
\end{abstract}

Keywords: Immersion $\cdot 3 \mathrm{D} \cdot$ Espacio recorrible $\cdot$ Inhabitable $\cdot$ Creativity

"Architecture is, above all, the design of immersions. Part of the ethics of the production of space is the responsibility for the atmosphere."

Peter Sloterdijk

\section{Introduction}

Architecture is an immersive and surrounding art that conditions the lives of those inhabiting it, because "to be inside the product of human work is like being a fish in the water, you dive in it completely, you live inside it, you belong to it..." (Valery 1921). 
Peter Sloterdijk considers architecture as being inherently a form of totalitarism because it deals with immersion, that is, the "production of an environment into which its inhabitants submerge, body and all.” (Sloterdijk 2006).

The immersive and totalitarian nature of architecture is one of the hurdles of architectural education. It has been traditionally avoided by focusing on exterior appearance or other virtuous graphical gimmicks to hide a superficial or nonexistent reflection on interior space.

This paper outlines our take on the problem, centered on training the immersive abilities of architectural apprentices while trying to answer the question: is it possible for an apprentice to validate the inhabitability of a three-dimensional figure she has produced by getting inside of it and traversing it? Furthermore, can she do it autonomously as a quality check of sorts (Lancho 2018) that reinforces learning?

\section{Immersion and Its Modes of Operation}

As architects we need to immerse ourselves in the spaces we create while designing them (Burgaleta 2010) so that we can validate our spatial insights and further on build them.

For us, imaginary immersion is the ability to make ourselves small and put ourselves into our creations. This is a fundamental ability that we need to develop and train to design spaces.

Architects have traditionally used plans and sections to produce spaces, while perspective drawings and scale models have been used for validation and communication to third parties of the space produced.

We alternate between two modes of operation while designing: emerging or designing "from the outside" in plan or section allows us to organize space with precise geometric relations and composition rules. Immersion or validation of space "from the inside", on the other side, let's us explore qualitative properties like light, material and perception of space.

This has been so since the days of Michael Angelo up until now with BIM (Building Information Modeling) (Fig. 1). 


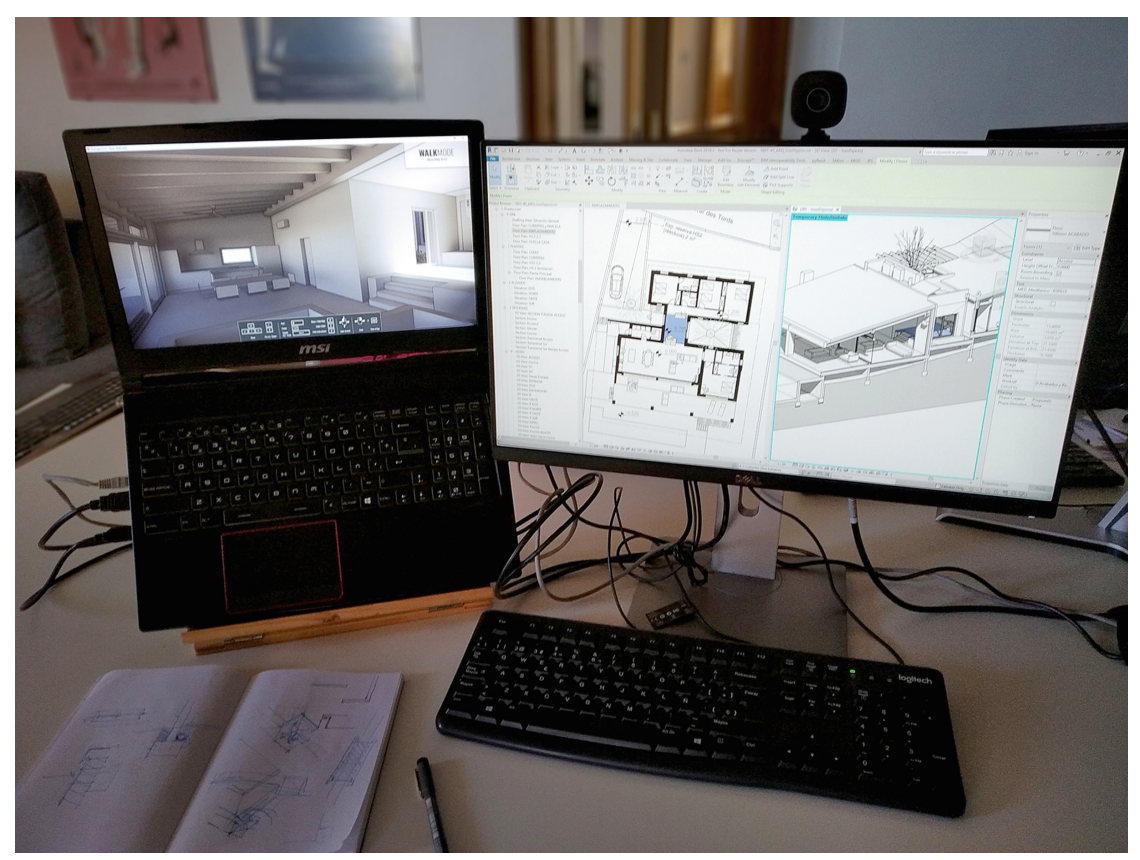

Fig. 1. Synchronic view of the project: immersive and analytic modes (ENSCAPE and Revit). Source: The authors

Immersion deals with "being inside", with being wrapped by space. For immersion to happen within an interfaced virtual environment like the one produced when playing a videogame, a number of requisites must be met (McMahan 2003) which we can transpose to the domain of producing inhabitable three-dimensional figures.

- The user's expectations about the immersive environment should match the graphic conventions of the virtual environment. That is: graphical quality, movement, etc., of the virtual environment must be believable enough.

- User actions must impact the immersive environment in a non-trivial way. That is: the user must be able to change the virtual world.

- The conventions of the immersive world must be consistent, even if they don't match those of the real world. In games this means that rules must be consistent although not real. For us it means that some rules of the real world must be consistently met in virtual space: some physical characteristics, light, shadows.

There are fascinating examples in videogames of processes of spatial creation, verification and change done by alternating between immersion and emersion.

May be the best game example is Minecraft, a block construction sandbox or "open world" where players alternate between (1) creative mode, that "quote" and (2) survival model, where players have finite resources, must feed themselves, fend monsters and wander the virtual world. This is: they must abide to consistent game rules and limitations (Fig. 2). 


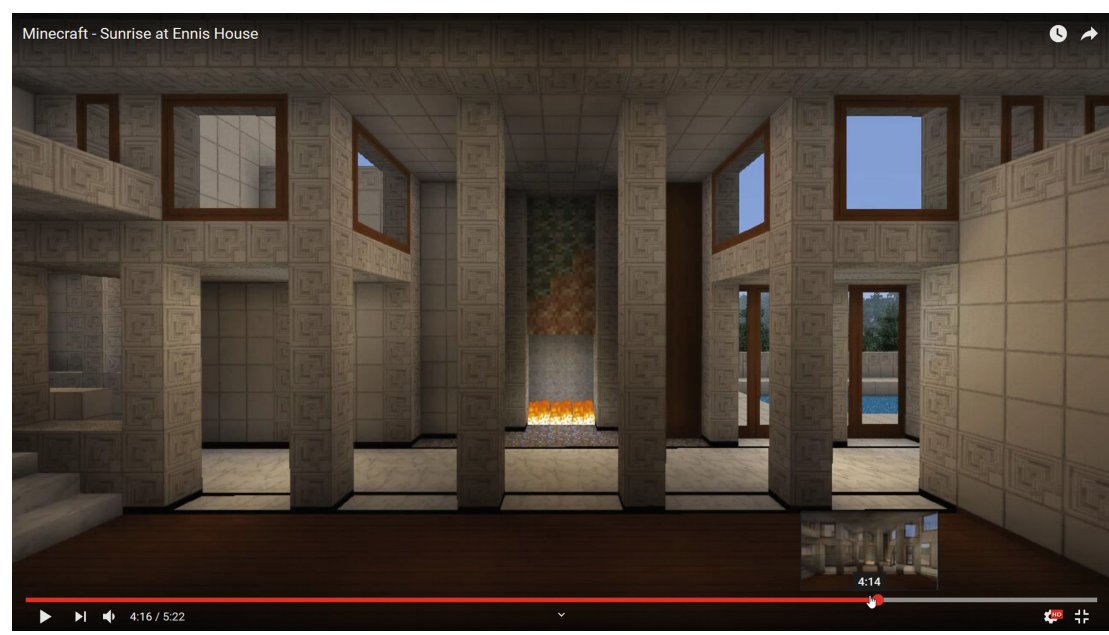

Fig. 2. Kevin Shull. Minecraft world modeled after Frank Lloyd Wright's Ennis House. Source: https://youtu.be/iSS4638VOiY

We have transposed both game operation modes to our teaching experience. We call them: analytic and immersive modes.

When representing space in immersive mode, we try to build an image of space as we are perceiving it, "from the inside", striving for an emotional approach. Our usual procedure when drawing is to place a figure within the space, akin to our own body, to explore spatial relations between the figure and the spaces significant elements to help us arrange our drawing by bringing measurements or references from reality to the paper in relation to the human figure. In immersive mode, everything revolves around our avatar. In immersive mode, material quality, light and shadows and all other perceptive matters qualify space.

In analytic mode, we create space through abstraction, "from the outside". It is a constructed drawing because nobody can actually see in plan, section or isometric. This abstraction helps us to reveal certain geometric and proportional relations of those spatial elements that constitute the space we are producing or studying. In this mode of operation, we are trying to develop spatial vision and analytical capabilities in our younger colleagues, we deal with how to simplify reality to be able to handle it. 


\section{The Course Experience}

The first-year graduate course Drawing, Analysis and Ideation (DAI), is organized as a practical workshop with three hour working sessions twice per week. In 2018-201960 apprentices and 2 facilitators shared a space for creation where the general working procedure consisted on the enunciation of a theme inspired or based on an artist's work and its subsequent collective development in class. Further work is also carried at home by the apprentices individually.

Our pedagogic objectives were aimed to:

1. Facilitate the circular process of production, validation and modification of inhabitable three-dimensional figures with open and cheap techniques, that are also simple and easy to learn and practice.

2. Facilitate the apprentices autonomous check of the inhabitability of their produced three-dimensional figures. This is done using analogous mechanisms to those of built environments: walking, looking around, seeing light and shadows, transparency, etc.

The first attempts to capture space by drawing in the course happened around the later third of the first semester, when apprentices have already spent some weeks being introduced to drawing techniques and exercises set up to open their minds and unchain their hands. This first spatial attempts are structured as a sequence of exercises where the field of vision is progressively widened, from the figure to the class's space. They deal exclusively with the immersive mode.

We use Alberto Giacometti's work and the way he builds his drawings and paintings with a connected mesh of lines as our main reference when drawing using figure as measurement for all things, with connected proportional relations (Fig. 3). 


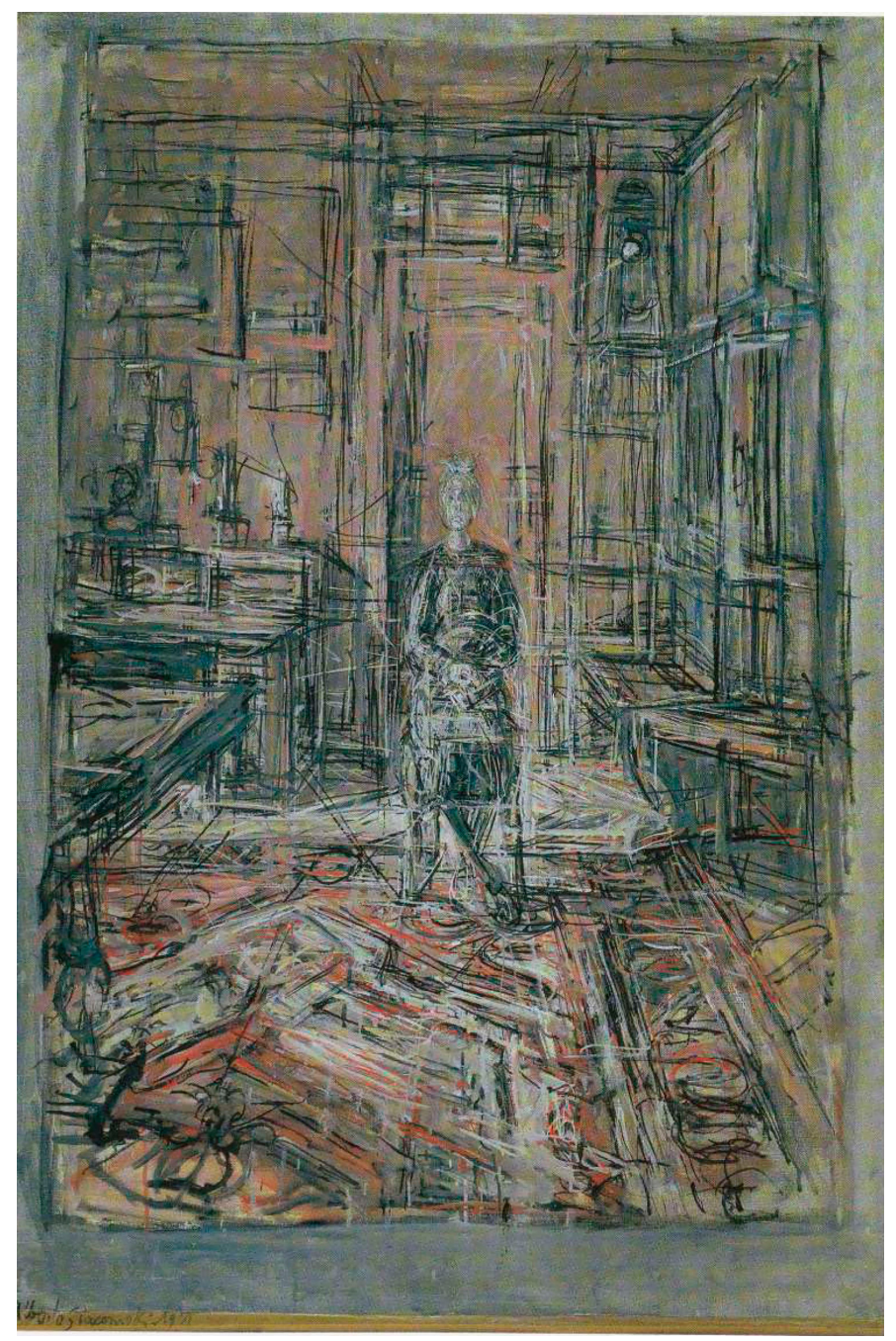

Fig. 3. Alberto Giacometti. Mother, 1950

The apprentice places himself in the class space facing a peer and the first proportions to be solved are those of the human figure in front of him. Attention must be focused on the size of the head in relation to the body, etc. This first approximation must be properly placed and corrected to prevent the background from "falling".

From there on we can begin to relate to the background, drawing ground and background simultaneously - with transparency - to "connect" the figure with known reference points in the background and slowly develop a believable image. The key to immersion in this stage is verisimilitude, not correctness (Fig. 4). 


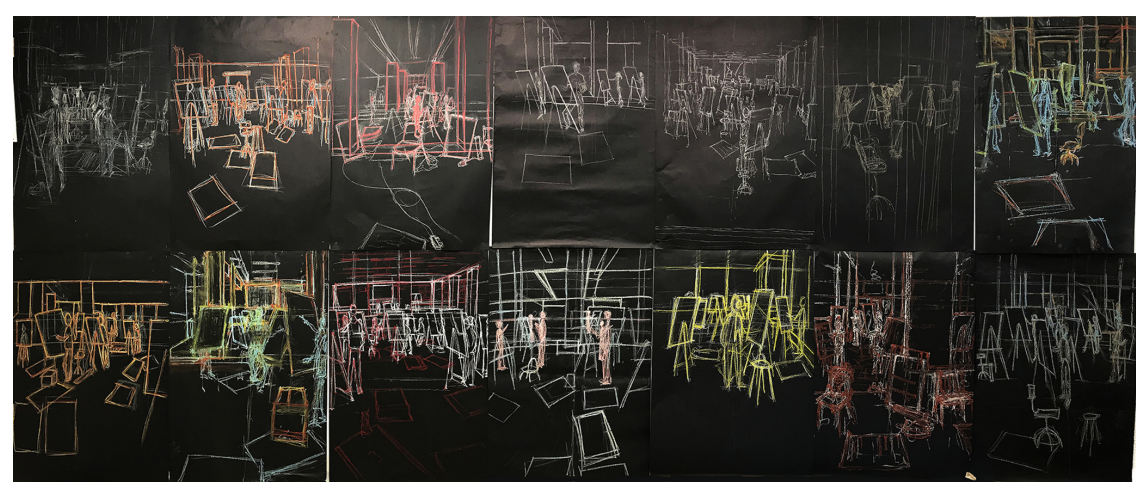

Fig. 4. The classroom. Immersive mode. Source: Course assignments.

Once we accomplish the immersive representation of space we switch to the analytic mode. We will build space "from the outside" now. The drawing will be centered in the position one occupies in the class and it is built as a recursive subdivision of the main constituent "boxes" of the space. Basic proportions are established via simple measurements (no measuring devices, just using visual estimations, counting steps, etc.) (Fig. 5).
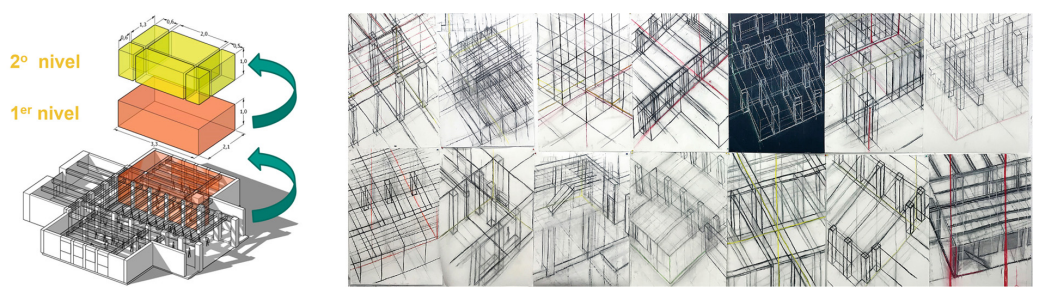

Fig. 5. The classroom. Analytical mode. Source: Course assignments.

To close this dual immersive/analytic approximation to spatial apprehension (because we are dealing with capturing space, not with inventing or producing it), we finish with an exercise called "My world in a box" inspired in the work of the Dutch architect and artist Willem Van den Hoed and Brazilian artist Lucia Koch. The apprentices must document their rooms, their immediate private space, creating an emotional connection with the space that helps their immersion, as they are dealing with their refuge or lair.

Alternating between immersive/emotional and analytical approaches, apprentices must produce photographic collages, drawings, models, an analytical drawing and 3D model.

We use artifacts in assignments because of their immediacy and tactile qualities, to foster color, texture and material exploration as well as lighting. They are cheap to make and must be easily modifiable to foster experimentation. They must not be bigger 

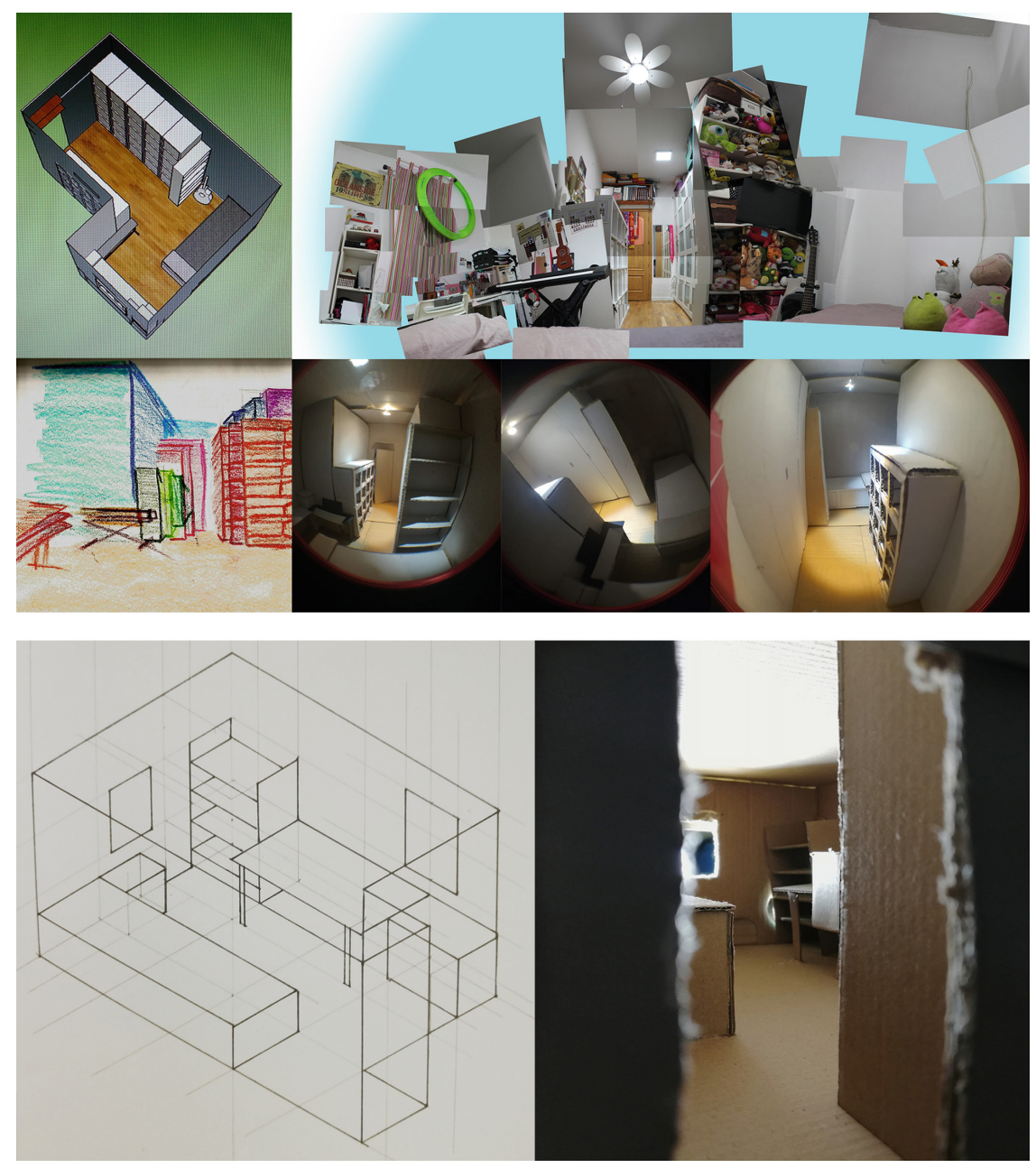

Fig. 6. Two examples of my world in a box. Photocollage, immersive drawing, 3D model and immersive physical artifact (up). Analytical vs Immersive approach (down). Source: Course assignments.

than a shoe box and should also allow peeking inside with a peephole viewer. We resort to the brass peephole viewer with wide angle lens like the ones used at our home's front doors. The low quality of the lens, along with the lighting (Rutkay y otros 2007), allows for the suspension of disbelief that enables the illusion of immersion (Fig. 6).

After this stage we begin another immersive/analytical process of spatial creation the end result of which must be an original spatial intervention. Students have to deliver a new space based on the present reality of their surroundings: one of the main stairs of the school of architecture building. 
We commence with space apprehension, where we survey the stairs by estimating proportional relations (no measuring tape used). We close this stage with a large format collective drawing of the chosen stairs. At this stage, the work relies mainly on the analytical model, constructing the space from the outside via plans, sections and isometric drawings. Thus, we reveal the geometric and proportional relations of the different elements that constitute the space we are analyzing (Fig. 7).

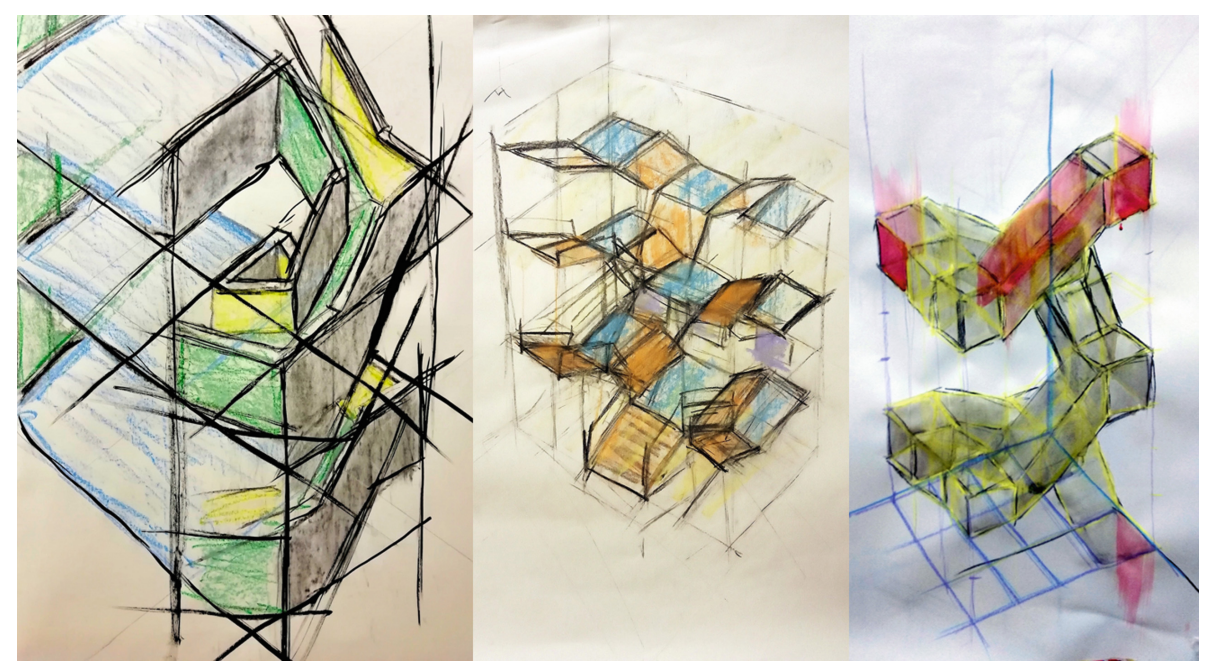

Fig. 7. Spatial analysis. Source: Course assignments.

From this point on we continue with a process of modification and design to produce an original spatial intervention. This is done through collective work sessions where each team member develops the design through different techniques: drawings, artifacts and 3D models. Intertwined with this sessions we allocate time to focus on other issues or different exercises to allow for creative expansion. This is meant to avoid too much pressure towards the outcome. We want to relieve that pressure to allow for investigation. We find that students fall too easily in the closed mode (Cleese 1991) and focus too much on the end result, which translates in poorly thought out proposals.

Apprentices deal now with the main difficulty when designing and imagining a space: to establish a pattern or some sort of structure we need to place elements. At the same time, this elements need of said pattern or structure to be arranged. Thus, in a circular process, to invent we test spatial arrangements. Those dispositions that persist or are kept, allow us to extract patterns that help structure the space again.

In this exercises, we foster the intersection of traditional and digital techniques. We believe that this produces the most fertile playground for students (Fig. 8). 


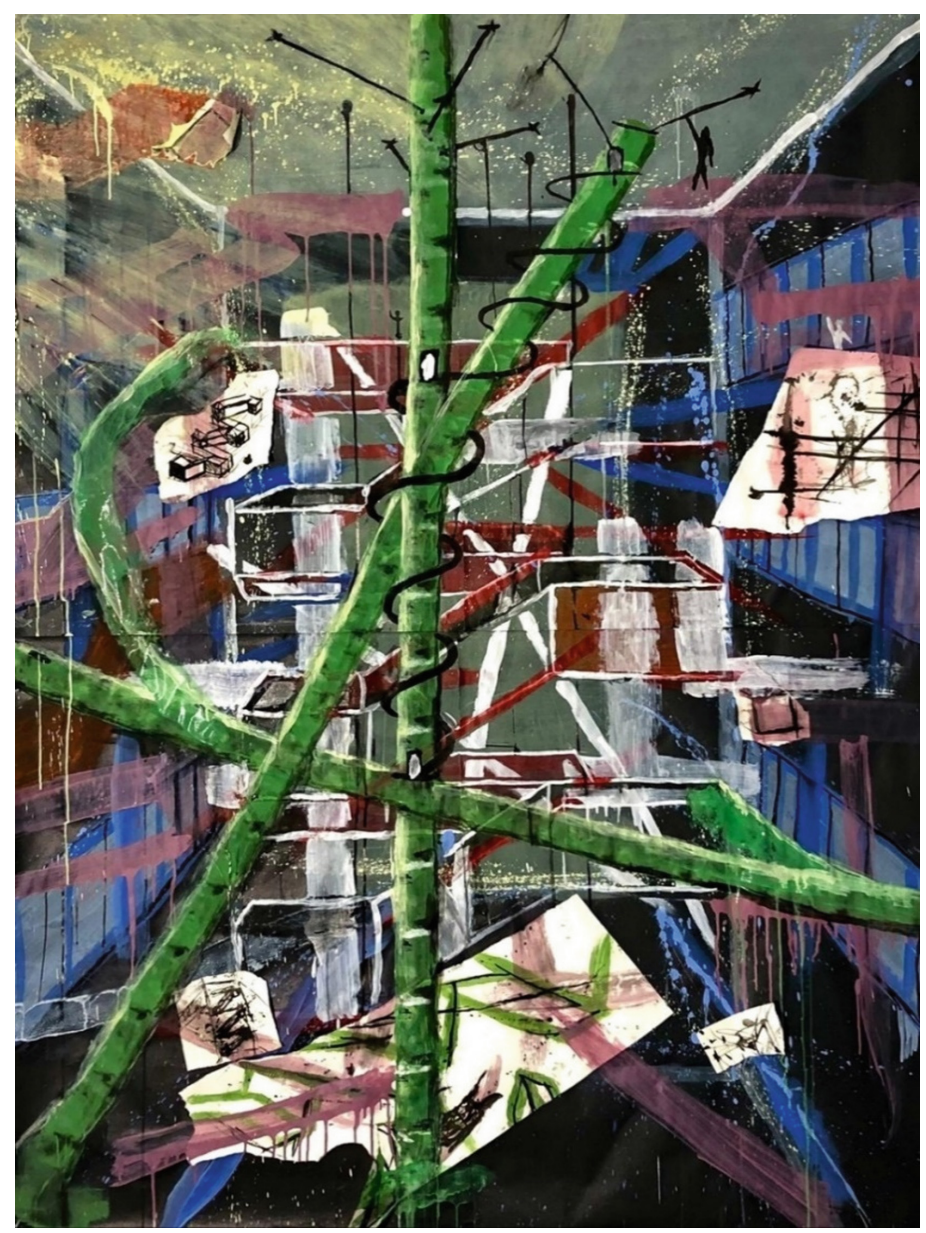

Fig. 8. Spatial proposal by one of the teams. This drawing becomes also $2 \mathrm{D}$ animation and $3 \mathrm{D}$ immersive model. Source: Course assignments.

We switch now to the immersive mode, working the space "from within", looking for an emotional approach to the matter.

At his stage, virtual immersice artifacts comprise the main novelty of the process. Contrary to other experiencias docentes with small groups and dedicated sesiones de formación, we had to simplify the whole process to fit it for a 60 novices group with very limited time (Valls et al. 2016).

Virtual artifacts were created in all purpose modelers like Sketchup or Rhinoceros by the apprentices while learning the tools without any introduction. We helped the 
process with flipped classroom video tutorials made by us (DAI 2019) and we also counted on the work done in other courses in the grade where this tools are used.

To enable the immersion in one's three-dimensional figure, get inside and walk around it as we would do in a videogame, we have used an interactive application compatible with the modelers used (ENSCAPE 2019). This app let's us abstract the complexities of rendering a believable space making it a seamless process for the user while modeling. It's main virtue is that, thanks to its tight integration with the modeler, the alternation between immersion and emmersion or design changes is very fluid with no calculations or configuration procedures as those in traditional render apps. This is made possible because the immersive model is generated by Enscape in realtime while we model: every change in the model is immediately transferred to the immersive realm. Let's remember that our ability to significantly alter the virtual space is key for our immersion and - above all - to change our own view of our proposal by switching between immersive and analytical modes.

Interactive virtual artifacts enhance our creativity while - simultaneously - force us to discipline by submitting ourselves to certain ground rules. This rules are a subset of all the complex restrictions a real space would have, but they nonetheless bound us to what is valid and what is not in such a space. We have to work a minimal set of inhabitability conditions to be met, specifically regarding changes in level, opening widths and slopes which are accessible.

Virtual spatial proposals must comply with the following limitations:

- They must contain some context reference to the space where the stair is placed. This can be fragments of the plan, significant walls, etc.

- They must be traversable: slabs, ramps, stairs that permit the virtual walk around.

- They must acknowledge human scale: the virtual avatar cannot walk over obstacles taller than $0,5 \mathrm{~m}$ or go through tight openings.

This last point provokes perplexity on apprentices when they open their virtual artifact in Enscape and the model vanishes. The virtual avatar has a height of 1,65 m and many models, while being proportionally correct, are not scaled properly. Thus, we have models that measure just a few millimeters in virtual space, disappearing because - in reality - it is just a grain of sand on the floor (Fig. 9). 

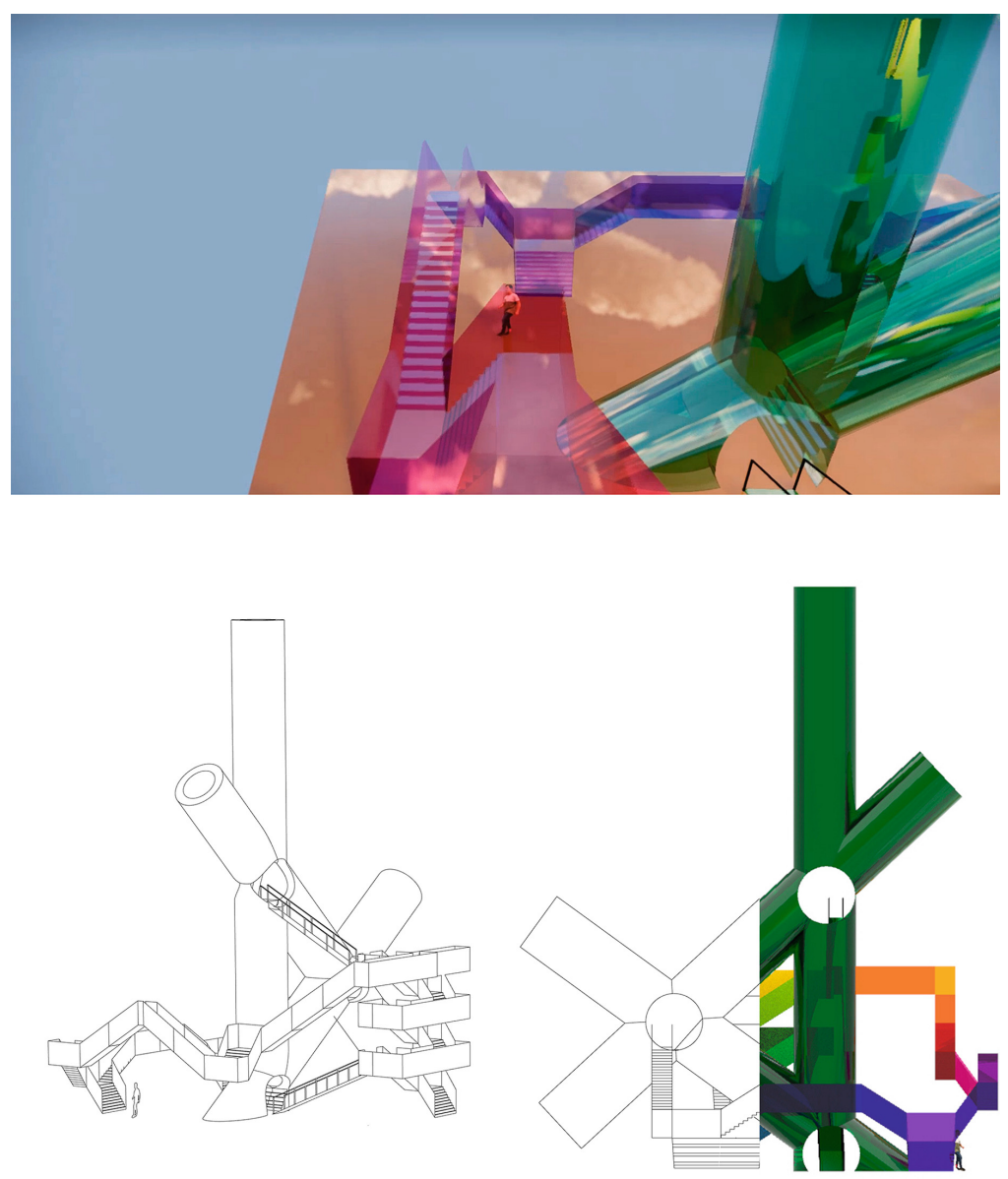

Fig. 9. Spatial proposal. ENSCAPE interactive virtual artifact (up) and 3D model in Rhinoceros. Source: Course assignments.

\section{Conclusion}

We pose the learning experience as an open challenge, where there is not a unique solution to the problem. We want to set up a learning space where apprentices can investigate and freely put forward ideas to create new outcomes from the starting material, following Johannes Huizinga's idea that "play is distinct from ordinary life, both as to locality and duration. This is its main characteristic: its secludedness, its limitedness. Play begins and then (at a certain moment) it is over. Otherwise, it's not play" (Huizinga 1938).

We also try to put forward the idea that creative action is a process that follows certain ground rules, requiring a system and a preparation, because we think that "creativity is not a talent, it is a way of operating" (Cleese 1991). 
The assignment sequence we have exposed is set up to allow apprentices to experiment a succession of moments of production and reflection alternating between analytical and immersive modes. Both states, however, are interwoven and inform what we do in each of them. Thus, our spatial proposal will be modified by our findings during immersion, so we will perform alterations that will produce yet another immersion check in a cyclic process until we are happy with the outcome or time has run out. We believe it is the change of our perspective during the dialectic of immersion/emersion that sparks those findings.

Apprentices value the creative freedom that an open approach poses, although it puts them in the situation of attempting to solve unclear or too open problems. They see that monumental failures can happen but that there is also "space for the exceptional and sometimes surprise for the hidden abilities one has" (quoted from the courses survey).

Awareness of one's own creative capacity may well be the biggest change we observe on our apprentices: they find out that they can envision spaces and that there are processes that let them visit their own creations generating a positive feedback loop that enables further creative outcomes.

What we, as educators, value above all is that apprentices break with the magical ideas about inspiration and understand that creation requires setting up a playing ground where enthusiasm and emotion rule. They must also understand that creative action also comes with highs and lows, moments of tension, but also joy and fun (Huizinga 1938).

Research on the design and production of spaces in virtual immersive environments is in a specially interesting stage. The procedure hereby shown can have huge possibilities in connection with the present advancements in interactive multiuser VR environments (Arkio 2019) where multiple users can immerse, build and modify the virtual space. There are other design and creative apps (Gravity Sketch 2019) connectable to domestic VR gadgets like HTC Vice or Occulus headsets, readily available in massive platforms like STEAM, which are opening a whole new field for creation in virtual environments and that we don't doubt that will eventually be revolutionary in our domain.

We know for a fact that we cannot create space "from within" all the time. We need to emerge from it in an iterative process that informs our design actions and gives us information to gradually develop it. From an architect's and educator point of view, the bridging of immersive virtual environments like Enscape, Arkio or Gravity Sketch and analytical design apps (which are the modelers we are used to) is the most fertile ground to explore.

\section{References}

Arkio Collaborative Design homepage. https://arkio.is. Accessed 23 Oct 2019

Burgaleta, P.: Marco teórico. Web site of course. https://barrachunky.wordpress.com/marcoteorico/presentacion/. Accessed 23 Oct 2019 
Burgaleta, P.: La Pedagogía de la iniciación en la creación arquitectónica: la inmersión y la emersión imaginarias, el espacio matriz y la propuesta incipiente. Rev. EGA (15), 138-147 (2010)

Cleese, J.: Creativity in Management 1991. https://youtu.be/Pb5oIIPO62g. Accessed 23 Oct 2019

DAI Espacios desde dibujos Youtube video. https://youtu.be/YJwS_HnIcHQ. Accessed 23 Oct 2019

ENSCAPE Real-Time Rendering \& Virtual Reality homepage. https://enscape3d.com. Accessed 23 Oct 2019

Gravity Sketch Empowering Creative Freedom homepage. https://www.gravitysketch.com/. Accessed 23 Oct 2019

Huizinga, J.: Homo Ludens. Alianza Editorial (1938)

Lancho, F.: "Máquinas constructivistas para el aprendizaje de procesos creativos". In: XVII Congreso Internacional de Expresión Gráfica Arquitectónica, Alicante 2018, vol. II, pp. 1401-1407 (2018)

McMahan, A.: Inmersion, engagement, and presence de the video game theory reader. Cap 3. pp 67-86 (2003)

Ruttkay, F., González, A., Atanasio, V.: Teaching and Learning the daylighting phenomenon in architecture with physical models. PLEA (2007)

Sloterdijk, P.: Architecture as an Art of Inmersion. In Interstices: J. Archit. Relat. Arts 105-109 (2006)

Valery, P.: Eupalinos o el arquitecto (1921)

Valls, F., Redondo, E., Fonseca, D., Garcia-Almirall, P., Subirós, J.: Videogame technology in architecture education. In: Kurosu, M. (ed.) Human-Computer Interaction. Novel User Experiences, pp. 436-447. Springer, Cham (2016) 